\title{
PERUBAHAN KEARIFAN LOKAL MAPALUS TANI DI KELURAHAN RURUKAN SATU KECAMATAN TOMOHON TIMUR
}

\author{
Cheril Anita Rantung \\ Jane Sulinda Tambas \\ Benny Adrian Berthy Sagay
}

Naskah diterima melalui Email agrisosioekonomi@unsrat.ac.id

: Jumat, 25 September 2020

Disetujui diterbitkan

: Jumat, 23 Oktober 2020

\begin{abstract}
This study aims to determine changes in local wisdom of Mapalus Tani in Rurukan Satu Subdistrict, East Tomohon District. This research was conducted from February 2019 to April 2019. This research was obtained through in-depth interviews with several sources, informants / respondents using interview guides and being interviewed directly. The sampling method was carried out by snowball. The results showed that there had been changes in the values, norms and organizational structure of Mapalus Tani as stated by all the informants, informants / respondents interviewed while on the equipment some respondents said there had been no changes. Among other values, there are changes where there are no longer customs such as ma'tambor, pontuong, rituals before leaving for the garden, as well as changes in habits when going to the garden. In the norm, among others, there was a change where there was no longer a rule for labor to change energy but changing energy could be replaced by money. I doubt too is no longer as strict as it used to be. The organizational structure of Mapalus Tani changed, among others, the leader of the Mapalus Tani was no longer a tumutuuz who became the leader of the customs and rituals in Mapalus Tani. There was also a change in the equipment where the rope commonly used in Mapalus Tani, which is usually made of forest ropes that spread across the trees, was replaced with plastic ropes. Nevertheless Mapalus Tani still exists and exists and carries out Mapalus activities despite the various changes that have occurred. People who are members of Mapalus Tani are assisted in overcoming / reducing the burden of financing their land management.
\end{abstract}

Keywords : Mapalus Tani, Local Culture

\section{ABSTRAK}

Penelitian ini bertujuan untuk mengetahui perubahan kearifan lokal Mapalus Tani di Kelurahan Rurukan Satu Kecamatan Tomohon Timur. Penelitian ini dilakukan pada bulan Februari 2019 sampai April 2019. Penelitian ini diperoleh melalui wawancara mendalam kepada beberapa narasumber, informan/responden dengan menggunakan panduan wawancara dan diwawancarai secara langsung. Metode pengambilan sampel dilakukan secara snowball. Hasil penelitian menunjukkan bahwa telah terjadi perubahan pada nilai, norma dan struktur organisasi Mapalus Tani yang dikemukakan oleh seluruh narasumber, informan/responden yang diwawancarai sedangkan pada peralatan beberapa responden mengatakan tidak terjadi perubahan. Pada nilainilai antara lain, terjadi perubahan dimana tidak dilakukan lagi adat istiadat seperti ma'tambor, pontuong, ritualritual sebelum berangkat ke kebun, serta terjadi perubahan pada kebiasaan waktu berangkat ke kebun. Pada norma antara lain terjadi perubahan dimana tidak ada lagi aturan tenaga harus ganti tenaga tetapi berubah tenaga bisa digantikan uang. Sangsi pun tidak lagi tegas seperti dulu. Susunan organisasi Mapalus Tani berubah antara lain, pemimpin Mapalus Tani tidak lagi menjadi atau disebut tumutuuz yang menjadi pemimpin adat dan ritualritual dalam Mapalus Tani. Terjadi juga perubahan pada peralatan dimana tali yang biasa dipakai dalam Mapalus Tani yang biasanya terbuat dari tali hutan yang merambat dipohon, digantikan dengan tali plastik. Walaupun demikian Mapalus Tani tetap ada dan eksis serta melakukan kegiatan Mapalus walaupun dengan berbagai perubahan yang terjadi. Masyarakat yang menjadi anggota Mapalus Tani terbantukan dalam mengatasi/mengurangi beban membiayai pengolahan lahannya.

Kata kunci: Mapalus Tani, Kearifan Lokal 


\section{PENDAHULUAN}

\section{Latar Belakang}

Manusia dengan kebudayaannya pada hakekatnya berkembang sebagai tanggapan aktif manusia terhadap lingkungan dimana dia hidup, tinggal dan menetap. Setiap tempat, daerah, suku, masyarakat mempunyai cara-cara yang menjadi tata nilai hidup bagi masyarakat tersebut untuk menjalin hubungan timbal balik antara manusia dengan sesamanya dan dengan alam lingkungannya. Hal ini yang diwariskan secara turun-temurun dari generasi ke generasi yang menjadi pengetahuan tradisional atau kearifan lokal yang dilakukan dan dikembangkan masyarakat tersebut dan bersifat unik pada lokasi dan masyarakat tertentu (Tambas, 2016).

Pada masyarakat Minahasa terdapat kearifan lokal yang disebut Mapalus yaitu suatu sistem atau teknik kerjasama untuk kepentingan bersama yang diwariskan oleh para leluhur dari tanah Toar dan Lumimuut dalam suku Minahasa yaitu dimana pengertiannya "manusia hidup untuk menghidupkan manusia lain" (Sumual, 1995)'. Dikemukakan oleh Luntungan (2003) Mapalus adalah gotong royong dengan dasar kerjasama bantu membantu dikalangan sejumlah orang di desa pada bagian masyarakat lain seperti masyarakat di Minahasa hakekat budaya gotong royong dapat terealisasi melalui budaya Mapalus.

Hal ini merupakan salah satu konsep "si tou tumou tou "dimana dalam pengertiannya "manusia hidup untuk memanusiakan orang lain". Dalam realitas kehidupan manusia orang Minahasa sejak rujuknya kebudayaan tersebut diaplikasikan dalam bentuk etos kerja Mapalus (atau disebut Maando dalam bahasa Tontemboan), sebagaimana dalam bentuk satu kelompok untuk mengerjakan pekerjaan secara bergiliran (Luntungan, 2003).

Koentjaraningrat (2003) mengatakan bahwa pada masyarakat pedesaan yang masih tradisional budaya gotong royong adalah merupakan ciri khas dan pandangan hidup yang sudah turun temurun. Budaya ini dalam kehidupan tiap masyarakatnya memiliki bentuk yang beraneka ragam sistim pelaksanaanya antara lain gotong royong yang berazaskan timbal balik (tenaga balas dengan tenaga) dan ada pula gotong royong yang hanya memenuhi kewajiban sebagai anggota masyarakat.
Gotong royong merupakan salah satu bentuk solidaritas masyarakat agraris tradisional, masyarakat ini terikat satu sama lain berdasarkan relasi sosial yang disebut ikatan keluarga dekat, letak geografis dan iman kepercayaan. Kata dasar Mapalus ialah palus yang antara lain artinya menuangkan dan mengarahkan, sehingga Mapalus mengandung makna suatu sikap dan tindakan yang didasarkan pada kesadaran akan keharusan untuk beraktivitas dengan menghimpun (mempersatukan) daya (kekuatan dan kepandaian) setiap personil masyarakat untuk memperoleh suatu hasil yang optimal sesuai tujuan yang telah disepakati sebelumnya (Sumual, 1995).

Pada awalnya Mapalus dilakukan khusus pada kegiatan-kegiatan yang berkaitan dengan bidang pertanian, mulai dari membuka lahan sampai memetik hasil atau panen yang disebut Mapalus Tani. Budaya Mapalus tidak hanya terbatas di bidang pertanian saja, melainkan juga diterapkan dalam setiap kegiatan yang bersifat sosial kemasyarakatan pada segala bidang kehidupan. Seperti dalam kegiatan-kegiatan upacara adat, perkawinan, kematian, dan sebagainya.

Mapalus adalah kegiatan seperti membuka lahan untuk pemukiman, pertanian, sawah atau ladang yang di lakukan secara gotong royong dan tolong menolong di antara suatu keluarga, desa dan antara anggota masyarakat (Turang, 1983; Rachbini, 1990). Masyarakat yang menjadi anggota Mapalus terbantukan dalam mengatasi/ mengurangi beban masyarakat dalam membiayai pengolahan lahannya karena menjadi anggota Mapalus untuk menggarap lahannya.

Saat ini dengan kemajuan teknologi dan meningkatnya kehidupan masyarakat dan bercukupan uang, maka kegiatan-kegiatan Mapalus mulai berkurang dan tergeser oleh pola kehidupan kota. Pada masyarakat Kota Tomohon, berdasarkan pra-survey Mapalus Tani sudah jarang dan tidak terdengar lagi dan jika ditanyakan tentang Mapalus Tani maka masyarakat akan menyebut Marawis. Pada saat pra-survey di Kecamatan Tomohon Timur Kotamadya Tomohon ketika ditanyakan tentang Mapalus Tani mereka mengatakan bahwa Mapalus Tani di Kecamatan mereka sudah tidak ada, yang sekarang ada adalah Marawis. Oleh karena itu penting untuk mengetahui bagaimana Mapalus Tani saat ini, bagaimana perubahannya. 
Kecamatan Tomohon Timur memiliki beberapa Kelurahan dan penulis tertarik dengan Kelurahan Rurukan Satu yang pernah beberapa kali di kunjungi dan juga melakukan praktek lapang dan mudah dijangkau dengan kendaraan umum serta memiliki keluarga jauh di sana, sehingga memudahkan untuk berkomunikasi.

\section{Pengertian Kearifan Lokal}

Kearifan lokal adalah nilai-nilai atau pandangan dari suatu tempat yang memiliki sifat bijaksana dan baik, yang diikuti dan dapat dipercayai oleh masyarakat dan sudah diikuti dan dipercayai oleh masyarakat di suatu tempat tersebut dan sudah diikuti secara turun temurun (Tambas, 2016).

\section{Pengertian Mapalus}

Pengertian kata Mapalus menurut Tumenggung (1971) sebagai berikut:

1. Mapalus artinya bekerja dengan berkawan beberapa orang serta bekerja dengan bergantiganti.

2. Mapalus adalah tolong menolong dengan dasar kerja sama untuk mencapai suatu maksud (berbakti untuk kepentingan umum).

3. Mapalus berarti tolong menolong karena seseorang telah menerima sokongan ia akan memberikan pertolongan.

Secara umum Mapalus artinya suatu bentuk kerja sama bantu-membantu sejumlah orang-orang sedesa dalam bentuk satu kelompok yang jumlahnya berkisar 10 sampai 40 orang, anggota kelompok tersebut memiliki kepentingan yang sama yang akan dipenuhi secara bergiliran menurut adat (Kalangi, 1971). Mapalus sebagai sebuah sistem kerja memiliki nilai-nlai etos seperti, etos resiprokal, etos partisipatif, solidaritas, responsilibitas, gotong royong, good leader, disiplin, transparasi, kesetaraan, dan kepercayaan (Umbas 2011).

Kelompok Mapalus dapat dibentuk berdasarkan pada kepentingan bersama oleh sejumlah individu yang bersedia bekerja sama atas dasar prinsip resiprositas yang dalam pelaksanaannya terorganisasi sebagai kegiatan dalam bentuk perkumpulan-perkumpulan (kumpulan). Seseorang yang ingin memenuhi suatu kebutuhan yang merupakan kebutuhan bersama, namun sulit dipenuhi secara perorangan, dapat membentuk suatu perkumpulan yang bertujuan untuk saling membantu dalam pemenuhannya (Koentjaraningrat, 2002).

\section{Pengertian Mapalus Tani}

Awalnya Mapalus dilakukan khusus pada kagiatan-kegiatan yang berkaitan dengan bidang pertanian, mulai dari membuka lahan sampai memetik hasil atau panen, tetapi seiring dengan perkembangannya budaya Mapalus tidak hanya terbatas di bidang pertanian, melainkan juga diterapkan dalam setiap kegiatan yang bersifat sosial kemasyarakatan dan hampir di segala bidang kehidupan. Dengan adanya Mapalus membuat masyarakat minahasa menjadi lebih bersaudara satu dengan yang lainnya tanpa memandang suku, agama dan ras (Umbas, 2011).

Dibentuknya kelompok Mapalus Tani untuk meringankan, mengatasi masalah, membantu, mendorong, serta memberdayakan masyarakat petani, ini harus berjalan sesuai dengan keinginan dan kemampuan kelompok baik anggota maupun pengurusnya. Kalau dahulu Mapalus Tani banyak ditunjukkan pada saling bantu-membantu dalam pekerjaanpekerjaan pertanian dari suatu kelompok yang berjumlah sekitar 20 orang, dengan prinsip timbal balik (disebut juga ma'ando dalam bahasa Tontemboan).

Gejala solidaritas ini tidak hanya terlihat pada kalangan-kalangankerabat, tetapi juga pada kalangan yang lebih luas lagi yang meliputi warga serukun tetangga, sekampaung, sekecamatan atau diluar minahasa dikenal dengan, misalnya kerukunan-kerukunan keluarga, kecamatan, subetnik, dan kawanua (Koentjaraningrat, 2009). Ada beragam kegiatan yang dijalankan dalam kelompok Mapalus, contohnya: kelompok Mapalus Tani berfungsi di bidang pertanian baik untuk membuka lahan, menanam panen serta pasarkan hasilnya yang akan dibagi bersama dengan anggota kelompok Mapalus ini .

Menurut (Kalangi 1982), dalam hal mengerjakan pekerjaan dalam bidang pertanian, tampak adanya saling bantu-membantu atas prinsip timbal balik. Selanjutnya tidak ada pemberian yang bersifat cuma-cuma, segala bentuk pemberian kembali atau imbalan. Karena itu dalam pemberian oleh seseorang kepada orang lain berlaku tukar-menukar pemberian antara pihak pemberi dan pihak penerima. Pertukaran tersebut memiliki fungsi penyokong kelangsungan hidup sosial didasarkan pada proses timbal balik dan saling melengkapi. 


\section{Rumusan Masalah}

Bardasarkan latar belakang maka yang menjadi pemasalahan dalam penelitian ini, Bagaimanakah Perubahan Kearifan Lokal Mapalus Tani di Kelurahan Rurukan Satu Kecamatan Tomohon Timur?

\section{Tujuan Penelitian}

Tujuan penelitian ini untuk mengetahui Perubahan Kearifan Lokal Mapalus Tani di Kelurahan Rurukan Satu Kecamatan Tomohon Timur.

\section{Manfaat Penelitian}

1. Penelitian ini diharapkan mampu memberikan informasi secara jelas terhadap instansi terkait seperti pemerintah, serta pihak-pihak yang berhubungan dengan pengambilan kebijakan.

2. Pengembangan ilmu pengetahuan yang berhubungan dengan kebudayaan dan bahan informasi bagi peneliti lainnya yang tertarik meneliti masalah budaya lokal.

3. Manfaat dalam penelitian ini bagi penulis adalah untuk meningkatkan pengetahuan tentang perubahan kearifan lokal Mapalus Tani di Kelurahan Rurukan Satu Kecamatan Tomohon Timur.

\section{METODE PENELITIAN}

\section{Lokasi dan Waktu Penelitian}

Penelitian dilaksanakan di Kelurahan Rurukan Satu Kecamatan Tomohon Timur. Penelitian ini telah berlangsung selama 3 bulan, mulai dari bulan Februari sampai April 2019.

\section{Metode Pengumpulan Data}

Data yang digunakan dalam penelitian ini adalah data primer dan data sekunder. Data primer adalah data yang diperoleh dari lapangan tempat penelitian melalui wawancara mendalam kepada para narasumber/informan/responden, juga dari observasi dan dokumentasi. Data sekunder yaitu data yang diperoleh dari instansi pemerintah Desa Rurukan Satu Kecamatan Tomohon Timur serta dokumen instansi yang relevan. Penelitian ini merupakan penelitian kualitatif dilakukan dengan melakukan wawancara mendalam kepada narasumber/ informan/responden. Narasumber/informan menurut Kamus Besar Bahasa Indonesia (KBBI) adalah orang yang mengetahui secara jelas atau menjadi sumber informasi; informan. Sedangkan responden adalah penjawab atas pertanyaan yang diajukan untuk keperluan penelitian. Narasumber/ informan dalam penelitian ini disebut juga dengan responden kunci.

\section{Metode Pengumpulan Sampel}

Pengambilan sampel menggunakan perspektif kualitatif yaitu penelitian tentang data yang dikumpulkan dan dinyatakan dalam bentuk kata-kata dan gambar, kata-kata disusun dalam kalimat yaitu kalimat hasil wawancara antara peneliti dan narasumber/informan/respoden. Penelitian kualitatif ditujukan untuk memahami fenomenafenomena sosial dari sudut perspektif partisipan. Partisipan adalah orang-orang yang diwawancarai, diobservasi, diminta memberikan data, pendapat, pemikiran, persepsinya (Sukmadinata, 2006).

Penetapan responden dalam penelitian ini akan dilakukan dengan menggunakan teknik bola salju (snowball) yang memungkinkan perolehan data dari satu responden ke responden lainnya. Pencarian informasi ini berhenti apabila tambahan responden tidak lagi menghasilkan informasi baru atau sudah berada pada titik jenuh. Responden kunci atau narasumber/ informan yang dipilih adalah Ketua Mapalus Tani dan tua-tua adat serta tokoh masyarakat dan responden adalah anggota kelompok Mapalus Tani di Kelurahan Rurukan Satu Kecamatan Tomohon Timur Kota Tomohon.

\section{Metode Analisis Data}

Teknik analisis data yang digunakan dalam penelitian ini adalah teknik analisis deskripstif kualitatif dengan melakukan proses analisis tersebut, maka data yang diperoleh akan memberi gambaran secara deskriptif dengan kata-kata tentang aspek-aspek yang menjadi tujuan penelitian yang kemudian akan memberikan jawaban atas masalah yang diteliti. 


\section{HASIL DAN PEMBAHASAN}

\section{Keadaan Topografi dan Demografi}

Tomohon adalah salah satu Kota di Provinsi Sulawesi Utara dengan luas adalah 147,21 Km2dari Kota Manado, ibukota Provinsi Sulawesi Utara. Penelitian ini dilaksanakan di Kelurahan Rurukan Satu yang merupakan Kelurahan yang ada di Kota Tomohon (BPS dalam angka Tomohon, 2019).

Kelurahan Rurukan terletak pada Kecamatan Tomohon Timur dengan luas wilayah 155.8 ha. Batas-batas wilayah Kelurahan Rurukan adalah sebagai berikut (sumber: Kantor Kelurahan Rurukan Satu, 2019):

Sebelah Utara : Kelurahan Rurukan

Sebalah Selatan : Kelurahan Rurukan

Sebelah Timur : Kelurahan Wewelen

Sebelah Barat : Kelurahan Rurukan

Jarak merupakan salah satu yang penting untuk kemajuan suatu kawasan. Kawasan Rurukan Satu merupakan kawasan yang berada di perbukitan, maka jarak tempuh merupakan hal yang sangat penting untuk pertimbangan, terlebih lagi masih banyak kondisi jalan yang kondisinya masih kurang layak atau rusak untuk dilalui kendaraan. Pada umumnya jarak antara Kawasan Rurukan Satu dengan pusat Kota Tomohon yaitu 5,3 km dengan waktu tempuh sekitar 15 menit dan jarak dari Kawasan Rurukan Satu ke Kota Manado yaitu $29 \mathrm{~km}$ dengan waktu tempuh sekitar 60-75 menit.

Luas wilayah Kelurahan Rurukan Satu adalah 155.8 hektar (ha), dengan pembagian cakupan wilayah untuk wilayah pemukiman 90,9 hektar (ha), lahan perkebunan 3,8 hktar (ha), dan tempat pemakaman 0,1 hektar (ha).

\section{Keadaan Umum Kelurahan Rurukan Satu}

\section{Penduduk Menurut Jenis Kelamin}

Jumlah penduduk Kelurahan Rurukan Satu menurut data tahun 2019 dapat dilihat pada Tabel 1.

\begin{tabular}{llrr}
\multicolumn{4}{l}{ Tabel 1. Penduduk Menurut Jenis Kelamin } \\
\hline No. & Jenis Kelamin & Jumlah & Persentase (\%) \\
\hline 1 & Laki-laki & 612 & 50,04 \\
2 & Perempuan & 611 & 49,96 \\
\hline \multicolumn{4}{l}{ sumber: Data Primer yang diolah, 2019}
\end{tabular}

\section{Penduduk Menurut Tingkat Pendidikan}

Pendidikan menjadi salah satu program prioritas baik pemerintah desa maupun masyarakat secara umum. Pendidikan memang telah menjadi penopang dalam meningkatkan sumber daya manusia Indonesia untuk pembangunan bangsa. Oleh karena itu, kita seharusnya dapat meningkatkan sumber daya manusia Indonesia yang tidak kalah bersaing dengan sumber daya manusia di Negara-negara lain. Pada Tabel 2 dapat dilihat jumlah penduduk Kelurahan Rurukan Satu bedasarkan tingkat pendidikan.

Tabel 2. Penduduk Menurut Tingkat Pendidikan

\begin{tabular}{clrr}
\hline No & Tingkat Pendidikan & Jumlah & Persentase (\%) \\
\hline 1 & Tamat Sekolah Dasar & 392 & 37,94 \\
2 & Tamat SLTA & 343 & 33,20 \\
3 & Tamat SLTP & 211 & 20,42 \\
4 & Tamat Sarjana (S1) & 37 & 3,59 \\
5 & Sedang TK & 25 & 2,42 \\
6 & Tamat D3 & 11 & 1,06 \\
7 & Tamat D1 & 10 & 0,97 \\
8 & Tamat D2 & 3 & 0,30 \\
9 & Tamat Sarjana (S2) & 1 & 0,1 \\
\hline & Jumlah & 1,033 & 100 \\
\hline
\end{tabular}

Sumber: Data Primer yang diolah, 2019

\section{Penduduk Menurut Mata Pencaharian}

Penduduk menurut mata pencaharian menjelaskan mengenai jenis-jenis mata pencaharian, Jenis-jenis mata pencaharian ini yang merupakan sumber pendapatan penduduk. Tingkat pendidikan pada dasarnya dapat mempengaruhi jenis pekerjaan yang ditekuni penduduk mayoritas mata pencaharian penduduk adalah petani, hal ini disebabkan karena sudah turun temurun, sejak dulu bahwa masyarakat adalah petani. Tabel 3 menunjukkan jumlah penduduk berdasakan jenis pekerjaan.

\begin{tabular}{|c|c|c|c|}
\hline No & Mata Pencaharian & Jumlah & Persentase $(\%)$ \\
\hline 1 & Petani & 109 & 54,22 \\
\hline 2 & Buruh & 35 & 17,41 \\
\hline 3 & Karyawan BUMN & 21 & 10,44 \\
\hline 4 & Pensiunan & 17 & 8,45 \\
\hline 5 & Wiraswasta & 11 & 5,48 \\
\hline 6 & TNI/Polri & 5 & 2,50 \\
\hline 7 & Karyawan perusahaan & 3 & 1,50 \\
\hline & Jumlah & 201 & 100 \\
\hline
\end{tabular}

\section{Penduduk Menurut Agama}

Penduduk menurut agama yang ada di Kelurahan Rurukan Satu dapat dilihat pada Tabel 4 bahwa semua masyarakat di Kelurahan Rurukan Satu memeluk Agama Kristen. 
Tabel 4. Penduduk Menurut Agama

\begin{tabular}{cccr}
\hline No. & Agama & Jumlah & Persentase (\%) \\
\hline 1 & Kristen Protestan & 825 & 66,21 \\
2 & Kristen Katolik & 421 & 33,79 \\
\hline & Jumlah & 1,223 & 100 \\
\hline Sumber: & Data Primer yang diolah, 2019 &
\end{tabular}

Sumber: Data Primer yang diolah, 2019

\section{Prasarana dan Sarana \\ Kelurahan Rurukan Satu}

Prasarana dan Sarana di Kelurahan Rurukan Satu Kecamatan Tomohon Timur.

a. Prasarana peribadah : Gereja 1 Unit

b. Prasarana kesehatan : Puskesmas 1 Unit

c. Prasarana Pendidikan :

Tk 1 Unit

SD 1 Unit

SMP 1 Unit

d. Sarana transportasi darat :

Bus Umum/Mobil

Pribadi 18/19 Unit

Truk/Pick up 21 Unit

Ojek 96 Unit

e. Prasarana dan Air Bersih :

Pengguna sumur

pompa $55 \mathrm{KK}$

Pengguna sumur gali $47 \mathrm{KK}$

Pengguna mata air $241 \mathrm{KK}$

\section{Deskripsi Responden Kunci (Narasumber/ Informan) dan Responden Penelitian}

Berdasarkan hasil yang didapatkan di lapangan, maka peneliti telah mewawancarai sebanyak 16 orang terdiri dari 13 responden dan 3 responden kunci (narasumber/informan). Adapun komposisi narasumber/informan dan responden menurut umur berusia 30 tahun sampai dengan 40 tahun terdiri dari 11 pria dan 5 wanita yang berpendidikan SMP (7 orang) dan SMA (8 orang). Responden sebanyak 13 orang tersebut terdiri dari anggota Mapalus Tani (8 orang) dan anggota marawis berjumlah 5 orang yang semuanya wanita.

Pada waktu pengambilan responden secara snowball maka responden berikutnya ditanyakan pada responden sebelumnya sehingga pada saat wawancara anggota Mapalus Tani, ditanyakan juga anggota kelompok marawis. Kelompok Marawis adalah kelompok yang berdiri sendiri yang bukan merupakan Mapalus Tani. Marawis berkembang sejak 7 tahun yang lalu (2013) dan hampir semua anggotanya adalah wanita. Responden kunci (narasumber/informan) masing-masing berusia 40 tahun, 42 tahun dan 71 tahun.
Sesuai wawancara pada saat supervisi dengan tua-tua adat, tokoh masyarakat dan ketua Mapalus Tani di Kelurahan Rurukan Satu bahwa Mapalus Tani saat ini di Kelurahan Rurukan Satu hampir semuanya adalah laki-laki. Sedangkan di marawis kebanyakan anggotanya perempuan.

\section{Hasil Wawancara}

- Hasil wawancara dengan responden kunci (narasumber/informan)

1. H.R, 40 Tahun, pendidikan Terakhir SMA yang merupakan konsultan pertanian sekaligus ketua Mapalus Tani saat ini, mengemukakan bahwa kegiatan Mapalus Tani biasanya kegiatan ini berlangsung pada saat akan menanam sampai pemanenan tanaman. Kegiatan ini diikuti oleh semua kelompok yang nantinya akan dibalas kembali (semua anggota akan mendapat giliran).

2. B.M, 71 tahun, pendidikan SMP, tua-tua kampung mengatakan bahwa dulu Mapalus Tani ini sifatnya lebih kebanyak orang tapi sekarang sudah berkelompok dan Mapalus Tani ada struktur organisasinya pemimpinnya biasa disebut ketua karena di Kelurahan Rurukan Satu ini sudah termasuk kota, selain ketua ada juga sekertaris, bendahara, seksi-seksi dan anggotannya. Paling berperan adalah sekertaris, karena sekertaris ini rangkap semua anggota yang termasuk di Mapalus Tani. Dahulu dalam melaksanakan Mapalus Tani ini ada tarian-tarian yang dipimpin oleh tumutuuz atau ketua adat. Setiap menjalankan Mapalus Tani ini mereka selalu menari dan bernyanyi, yang menari dan menyanyi ini termasuk dalam anggota Mapalus Tani. Anggota Mapalus Tani ini setiap bekerja mereka bernyanyi dan tentunya ada yang memimpin tarian dan nyanyian.

3. A.P, 42 Tahun, pendidikan terakhir SMA, tokoh masyarakat mengatakan bahwa. Mapalus Tani tetap ada di Kelurahan Rurukan Satu walaupun terjadi banyak perubahan tetapi intinya bahwa Mapalus Tani itu tetap menggunakan tenaga ganti tenaga walaupun bisa saja orang yang tidak hadir dan berhalangan mengganti tenaganya dengan uang yang kalau dahulu tidak bisa dan tetap harus dicarikan tenaga pengganti. Mapalus 
Tani ini bukan marawis dan beda dengan marawis. Biasanya marawis ini sama dengan menabung karena mereka menjual tenaga dan uang/upah ini di bagi pada saat hari raya dan biasanya di terima sebelum hari raya. Marawis ini petani juga tapi dibayar dan perbedaan nya dengan Mapalus Tani adalah Mapalus Tani harus orang itu kalau marawis bisa digantikan dengan orang lain atau bisa dibayar atau juga disaat mendapat giliran, giliran itu di jual ke orang lain yang butuh tenaga, jadi tidak harus selalu di lahan.

- Hasil Wawancara dengan 13 orang responden anggota Mapalus Tani (8 orang) dan Marawis (5 orang) :

1. H.A, 32 Tahun, Pendidikan terakhirSMA, bekerja sebagai petani. Menurut responden Mapalus Tanisudah ada dari dulu dan turun temurun dari nenek moyang. Dalam kegiatan Mapalus Tani ini tentunya melakukan sistem berkelompok, (baku-baku bantu). Tenaga ganti tenaga dan sekarang juga sudah ada tenaga ganti uang.

2. L.K, 37 Tahun. Pendidikan terakhir SMA bekerja sebagai petani. Menurut responden Mapalus Tani sudah ada dari dulu dan turun temurun dari nenek moyang. Menurut responden yang umurnya masih bisa dikatakan muda, kegiatan Mapalus ini sangat membantu untuk kehidupannya yang sudah bisa melatih diri untuk saling membantu.

3. D.K, 42 Tahun pendidikan terakhir SMA bekerja sebagai petani. Menurut responden Mapalus Tanisudah ada dari dulu dan turun temurun dari nenek moyang. Mapalus Tani ini sangat penting dalam keseharian dimana saling membantu, saling gotong royong untuk meringankan segala pekerjaan atau kebutuhan hidup. Dalam menjalankan Mapalus Tani ini menggunakan sistem bergilir dimana semua anggota akan mendapat giliran Mapalus dalam bidang pertanian.

4. M.K, 59 tahun. Pendidikan terakhir SMP, bekerja sebagai petani.Menurut responden Mapalus Tanisudah ada dari dulu dan turun temurun dari nenek moyang. Menurut responden bahwa Mapalus Tani sering disebut baku-baku bantu, Mapalus Tani ini menggunakan sistem bergilir atau semua anggota kelompok Mapalus Tani akan mendapat bagian.
5. Y.K, 35 Tahun, pendidikan terakhir SMA petani. Menurut responden Mapalus Tani sudah ada dari dulu dan turun temurun dari nenek moyang. Menurut responden bahwa keikutsertaannya dalam Mapalus Tani ini melalui ikatan keluarga dan kerabat. Dengan kewajiban menjadi anggota kelompok membawa ketentuan yang telah di sepakati harus di penuhi.

6. A.K, 49 Tahun, pendidikan terakhir SMP, pekerjaan petani. Menurut responden Mapalus Tani sudah ada dari dulu dan turun temurun dari nenek moyang. Menurut responden Mapalus pertanian sangatlah membantu untuk setiap kehidupan keluarga yang bertani karena dapat meminimalisir dana. Mapalus Tani ini menerapkan sistim tolong menolong yang menjalin kebersamaan antar sesama yang dilakukan secara berkelompok.

7. J.S, umur 36 tahun, Pendidikan terakhir SMA pekerjaan petani. Menurut responden bahwa keikutsertaanya dalam kegiatan Mapalus ini melalui ikatan keluarga dan lingkungan sekitar. Kewajiban yang harus dibawa sesuai dengan ketentuan yang telah di tetapkan di kelompok. Menurut responden bahwa pelaksanaan Mapalus Tani di Kelurahan Rurukan Satu menggunakan sistem gotong royong dengan sistem tenaga ganti dengan tenaga dengan pembagian jam kerja mulai pukul 07.00-15.00.

8. J.K, 42 Tahun, Pendidikan terakhir SMP, Pekerjaan Tani. Mapalus Tani ini "sangat ba bantu setiap kehidupan keluarga yang ba tani”. Kegiatan Mapalus Tani ini menerapkan sistem tolong menolong yang menjalin kebersamaan antar sesama yang dilakukan secara berkelompok. Keikutsertaan dalam kelompok Mapalus Tani ini karena faktor lingkungan dan kekerabatan. Adapun kewajiban yang musti torang bawah dalam kelompok ini yaitu musti maso tenaga deng sapa yang jadi giliran dorang musti sadia bibit. Pelaksanaan kegiatan Mapalus Tani ini menggunakan sistim gotong royong saling membantu satu dengan yang lain.

9. F.P, 47 Tahun, pendidikan terakhir SMA pekerjaan petani. Kegiatan Marawis yang telah responden ikuti yaitu kegiatan bergilir dimana setiap anggota akan mendapat giliran dengan sistem tenaga ganti tenaga atau uang diganti dengan tenaga. 
10. F.P, 47 tahun, pendidikan terakhir SMA pekerjaan petani. Menurut responden Marawis itu sama dengan manfaat tenaga, bekerja di kebun sambil di gaji dan marawisini ada sejak 5 tahun yang lalu. Yang menjalankan Marawis ini adalah orang-orang di Kelurahan Rurukan Satu yang pembagian jam kerjanya dari jam 07.00-15.00 atau sampai dengan selesai. Yang menjalankan Marawis ini adalah kami semua yang termasuk dalam anggota Marawis dan pelaksanaan Marawis ini dilakukan di kebun sendiri, di kebun anggota Marawis atau di kebun orang lain yang siap memberi upah. Menurut responden, responden mengikuti marawis ini karena membantu ekonomi keluarga.

11. S.S, 40 Tahun, pendidikan terakhir SMP pekerjaan petani. Menurut responden Marawis adalah manfaat tenaga bekerja di kebun dan digaji, Marawis ini sudah ada sejak 7 Tahun yang lalu dan yang menjalankan Marawis ini adalah kami sebagai anggota Marawis. Pelaksanaan Marawis ini di kebun anggota Marawis dan dikebun orang lain. Menurut reponden mengikuti Marawis ini sangat membantu dalam mencukupi kebutuhan ekonomi begitu juga pelaksanaan Marawis ini dilakukan 3 kali dalam 1 minggu.

12. F.K, 43 Tahun, pendidikan terakhir SMA pekerjaan petani. Menurut responden pelaksanaan Marawis di Kelurahan Rurukan menggunakan sistim gotong royong tetapi tenaga diganti (di bayar) dengan uang dengan pembagian jam kerja mulai dari pukul 07.0015.00. Menurut responden bahwa kegiatan ini sangat membantu ekonomi dalam keluarga saya mungkin bukan cuma saya tapi semua yang mengikuti Marawis ini dalam hal membantu dalam ekonomi. Upah yang kami kumpulkan dalam setiap mengikuti Marawis ini bisa langsung di ambil sehabis kerja atau nanti di ambil akhir tahun, " kalo kita biasa ambe akhir taon, mar kalo memang so perlu skli baru kita ambe pas abis kerja ". Saat kami dikebun kami langsung membagi tugas mulai dari membersihkan lahan sampai membuat bedengan dan dalam 1 minggu ada 3 kali kerja. Menurut responden di marawis ini ada pemegang buku yang bertugas mengatur jadwal dan memberi upah.
13. E.P, 30 Tahun, Pendidikan terakhir SMP, pekerjaan tani. Menurut responden Marawis ini sangat sekali membantu dalam kebutuhan ekonomi karena Marawis ini adalah memanfaatkan tenaga bekerja di kebun sambil di gaji/upah. Pelaksanaan Marawis ini adalah di kebun sendiri, kebun anggota Marawis atau kebun orang lain yang membutuhkan tenaga tambahan dan tentunya siap untuk memberi kita upah. Pelaksanaan marawis ini dalam 1 minggu ada 3 kali menjalankan Marawis biasannya di hari senin, rabu dan kamis/jumat.

\section{Pembahasan}

\section{Pelaksanaan Mapalus Tani dan Perubahannya. \\ - Pelaksanaan Mapalus Tani}

Saat ini Mapalus Tani di Kelurahan Rurukan Satu hanya ada satu kelompok tani yang dinamakan "Maesa-esaan". Mapalus Tani ini ada struktur organisasinya, pemimpinnya disebut ketua, selain ketua ada juga sekertaris, bendahara, dan anggotanya. Sekarang ini yang paling berperan adalah sekertarisnya karena sekertaris ini rangkap semua tugas-tugas administrasi di Mapalus Tani. Ketika menjalankan Mapalus Tani ini sudah ada kesepakatan bersama dalam melakukan Mapalus Tani yaitu jam kerja dari jam 7 pagi sampai jam 3 sore. Dahulu ada pemimpin Mapalus yang berperan sebagai pembuat keputusan dalam kegiatan ritualritual Mapalus dahulu terdapat banyak anggota yang berjumlah 40-50 orang dalam satu wilayah/desa.

\section{Tanggapan Masyarakat Terhadap Budaya MapalusTani dan Marawis}

Tanggapan masyarakat terhadap Mapalus Tani masih baik karena mereka masih ikut dalam Mapalus Tani dan masih ada organisasinya, yang walaupun hanya satu Mapalus Tani. Mereka juga menanggapi baik adanya Mapalus Tani yang bisa membantu mereka dalam bertani.

Marawis ditanggapi baik oleh masyarakat karena dengan Marawis mereka mendapatkan penghasilan tambahan, karena tenaga mereka dibayar/diberi upah langsung. 
Tabel 5. Ringkasan Perubahan Kearifan Lokal Mapalus Tani di Kelurahan Rurukan Satu Kecamatan Tomohon Timur Kota Tomohon

\begin{tabular}{|c|c|c|c|}
\hline No & Komponen & Unsur-unsur & Perubahan yang terjadi \\
\hline 1. & - Nilai & $\begin{array}{l}\text { - Kepercayaan } \\
\text { \& adat istiadat }\end{array}$ & $\begin{array}{l}\text { - Kehadiran dan kebersama- } \\
\text { an, terjadi perubahan } \\
\text { dimana dulu tenaga harus } \\
\text { digantikan dengan tenaga } \\
\text { sekarang tenaga bisa } \\
\text { digantikkan dengan uang. } \\
\text { - Mapalus Tani yang dulu } \\
\text { saat memulai aktifitas } \\
\text { mereka melakukan upacara } \\
\text { adat berupa pontuang, } \\
\text { ma'tambor, ma'zani. } \\
\text { Setelah melakukan upacara } \\
\text { adat petani langsung } \\
\text { melakukan kegiatan } \\
\text { mereka di kebun, tetapi } \\
\text { sekarang berbeda dengan } \\
\text { dulu karena sekarang ini } \\
\text { saat melakukan kegiatan di } \\
\text { kebun mereka hanya } \\
\text { menyanyikan lagu untuk } \\
\text { membuat mereka lebih } \\
\text { semangat bertani di kebun } \\
\text { dan nyanyian mereka itu } \\
\text { secara spontan tanpa } \\
\text { komando. }\end{array}$ \\
\hline 2. & - Norma & $\begin{array}{l}\text { - Ketentuan } \\
\text { waktu }\end{array}$ & $\begin{array}{l}\text { - Tidak ada lagi sanksi adat } \\
\text { yang apabila tidak hadir } \\
\text { akan dipermalukan atau } \\
\text { dikucilkan karena norma- } \\
\text { norma adat tidak berlaku } \\
\text { seperti/sekuat dulu. } \\
\text { - Ketentuan waktu yang dini } \\
\text { hari 04.30 telah bergeser } \\
\text { menyesuaikan dengan } \\
\text { waktu kerja yaitu pukul } \\
07.00 \text { pagi }\end{array}$ \\
\hline 3. & $\begin{array}{l}\text { - Struktur } \\
\text { Organisasi }\end{array}$ & $\begin{array}{l}\text { - Pengurus } \\
\text { Mapalus Tani }\end{array}$ & $\begin{array}{l}\text { - Kelompok Mapalus Tani } \\
\text { dahulu tersusun mulai dari } \\
\text { pemimpin Mapalus Tani/ } \\
\text { ketua, sekertaris, pemimpin } \\
\text { tarian, pemegang ma } \\
\text { 'tambor dan pemimpin } \\
\text { nyanyian serta anggota } \\
\text { Mapalus Tani. Sekarang } \\
\text { struktur organisasi terdiri } \\
\text { dari ketua, sekertaris dan } \\
\text { anggota, ketua yang } \\
\text { menentukan jadwal dan } \\
\text { sekertaris yang mengatur } \\
\text { semua kegiatan Mapalus } \\
\text { Tani. } \\
\text { Jumlah anggota Mapalus } \\
\text { Tani dahulu sekitar } 30 \\
\text { sampai dengan } 70 \text { orang } \\
\text { tetapi saat ini hanya } 13 \\
\text { orang. }\end{array}$ \\
\hline 4. & -Peralatan & $\begin{array}{l}\text { - Alat yang di } \\
\text { pakai }\end{array}$ & $\begin{array}{l}\text { - Peralatan yang dipakai } \\
\text { petani dahulu adalah } \\
\text { peralatan petani pada } \\
\text { umumnya seperti cangkul } \\
\text { /pacol dan parang/peda, } \\
\text { garo-garo tanah/garu dan } \\
\text { bulu kecil atau tali hutan } \\
\text { dari pohon yang sekarang } \\
\text { ini digantikan tali plastik } \\
\text { atau rafia. }\end{array}$ \\
\hline
\end{tabular}

\section{KESIMPULAN DAN SARAN}

\section{Kesimpulan}

Berdasarkan hasil penelitian dan pembahasan yang telah di kemukakan, maka dapat disimpulkan bahwa telah terjadi perubahan pada kearifan lokal Mapalus Tani. Perubahanperubahan itu terjadi pada nilai, norma, struktur organisasi juga peralatan. Perubahan pada nilai, terjadi pada nilai kebersamaan, kepercayaan dan adat istiadat. Pada norma, perubahan terjadi pada peraturan/cara, sangsi adat dan ketentuan waktu. Perubahan pada struktur organisasi Mapalus Tani, terjadi pada jumlah anggota dan keberadaan anggota.

Kearifan lokal Mapalus Tani dahulu dalam struktur organisasinya, pemimpin Mapalus Tani adalah juga pemimpin adat. Perubahan pada peralatan terjadi pada pemakaian tali hutan yang saat ini telah digantikan dengan tali plastik. Kearifan lokal Mapalus Tani masih tetap ada dan eksis sampai dengan saat ini, di Kelurahan Rurukan Satu Kecamatan Tomohon Timur walaupun terjadi beberapa perubahan. Kearifan lokal Mapalus Tani bukan Marawis. Marawis sistemnya lebih ke ekonomi dengan menetapkan upah dan diberikan upah sesuai pekerjaan.

\section{Saran}

1. Usaha untuk melestarikan nilai budaya Mapalus Tani perlu dilakukan secara intensif, baik dari kalangan masyarakat maupun kalangan pemerintah Kelurahan. Keberadaan Mapalus Tani tidak seperti dulu lagi dan di Kelurahan Rurukan Satu hanya tinggal satu kelompok saja. Perubahan-perubahan terhadap nilai budaya Mapalus Tani ini akan berdampak pada masyarakat dalam mempertahankan nilai budaya Mapalus Tani.

2. Bagi kalangan generasi muda diharapkan perlu menanamkan kesadaran tentang pentingnya mempertahankan kelestarian nilai budaya sebagai pengetahuan kearifan lokal yang perlu dipertahankan dan dilestarikan.

3. Bagi pemerintah desa diharapkan perlu memberikan motivasi serta memberikan bimbingan kepada masyarakat untuk tetap melestarikan nilai budaya Mapalus Tani secara langsung akan dapat membantu masyarakat dalam bertani dan memenuhi kebutuhan hidupnya. 


\section{DAFTAR PUSTAKA}

Anonimous 2020. Hingga Mei 2020, Ekspor Pertanian Saja yang Tumbuh Positif. Berita Satu. https://www.beritasatu. com/elvira-anna-siahaan/ ekonomi / 645 237/hingga-mei-2020-ekspor-pertaniansaja-yang-tumbuh-positif.

Kalangi, P. 1971. Kebudayaan Minahasa, Berita Antropologi Jilid II No. 4 Jakarta.

Koentjaraningrat dkk. 2002. Manusia dan Kebudayaan di Indonesia, Djambatan, Jakarta.

Koentjaraningrat. 2009. Pengantar Ilmu Antropologi. Jakarta Rineka Cipta.

Rachbini, D.J. 1990. Petani, Pertanian Subsisten dan Kelembagaan Tradisional. Prisma 2.
Sukmadinata, 2006. Metode Penelitian Kualitatif. Bandung : Graha Aksara.

Sumual,H.N., 1995. Baku Beking Pande. Bina Insani. Jakarta.

Tambas Jane Sulinda, 2016. Perubahan Maneke: Studi kearifan lokal pada masyarakat Pulau-Pulau Kecil di Kabupaten Kepulauan Sangihe. Disertasi Doktor. Universitas Brawijaya.

Turang, J. 1983. Mapalus di minahasa, Posko Operasi Mandiri.Daerah tingkat II Kabupaten Minahasa. Tomohon.

Umbas, V. 2011. The Mapalus Way. Https://cahayasiang.net/2011/01/13/M apalus-gagasan-ajaran.17 Maret2017. 